\title{
0 professor e a EaD: será que o docente está preparado para essa realidade?
}

The teacher and distance learning: are the teachers prepared for this reality?

\author{
Claudia Almeida Rodrigues*
}

Resumo: O crescimento da EaD no Brasil nos últimos anos tem levado à discussões acerca da formação dos profissionais da educação que trabalharão nessa modalidade de ensino. Percebe-se que as instituições de formação de professores não tem dado a devida importância à modalidade de ensino a distância, nem ao letramento digital do futuro professor. É preciso que se prepare o professor em sua formação inicial para trabalhar na $\mathrm{EaD}$, visto que essa modalidade de ensino pode ser uma alternativa para mitigar os problemas educacionais existentes no Brasil.

Palavras-chave: formação de professores, letramento digital, crescimento da Ead

Abstract: The increase of distance education in Brazil in recent years has led to discussions about the formation of education professionals who will work in this type of educational modality. It is perceived that the institutions of teacher education have given less importance to distance education, or the digital literacy of the future teachers. It is necessary to prepare teachers in their initial training to work in DL, since this type of education can be an alternative to mitigate the existing educational problems in Brazil.

Keywords: teacher education, digital literacy, increase of distance education

Durante discussões desenvolvidas pela comunidade aprendente no curso de especialização a distância, Ensino de Línguas Mediado por Computador, promovido pela Faculdade de Letras da Universidade Federal de Minas Gerais, na disciplina, Introdução à EaD, ministrada pela professora Ana Cristina Fricke Matte, levantou-se questões sobre a importância da formação do professor para a implantação de um projeto sólido de educação a distância em bases preconizadas pelos Referenciais de Qualidade para essa modalidade de ensino.

Diante dessa discussão, passou-se a questionar se o professor brasileiro, em sua formação inicial e mesmo continuada, é preparado para lidar com a nova realidade que se infunde na educação a partir do desenvolvimento das novas tecnologias da informação e comunicação e a disseminação dos cursos na modalidade a distância. Será que os cursos de formação de professores contemplam em suas grades curriculares disciplinas com essa abordagem, visto que pela nova LDB $20 \%$ da carga horária dos cursos podem ser oferecidos na modalidade a distância? Qual o perfil do professor para

\footnotetext{
* Mestre em Linguística pela Universidade Federal de Uberlândia. Doutoranda em Estudos Linguísticos pela Universidade Federal de Uberlândia, claudiarodriguesmurta@gmail.com.
} 
atuar na EaD para que ele seja um multiplicador dessa modalidade de ensino? O objetivo desse artigo é levantar a discussão em torno da formação de professores no Brasil para atuarem na $\mathrm{EaD}$.

A década de 90 do século XX, em nosso país, destacou-se pela implementação de políticas neoliberais, sobretudo durante o governo do presidente Fernando Henrique Cardoso. Foram implementadas mudanças na educação, e no país como um todo, com base no ideário econômico vigente, alterações essas que seguiram o movimento instaurado mundialmente pela UNESCO e pelo BIRD/Banco Mundial, este último em sintonia com o Fundo Monetário Internacional (FMI). A reestruturação da educação resultou, no Brasil, na concretização do Plano Decenal de Educação para Todos e na reforma educacional que produziu diretrizes e referenciais curriculares, como os PCNs e avaliações dos diversos níveis do ensino, como o Exame Nacional do Ensino Médio (ENEM), o Exame Nacional de Cursos (ENADE) etc.

As políticas públicas e educacionais de formação de professores, para todos os níveis e modalidades de ensino, passariam a ser oferecidos preferencialmente pelos Institutos Superiores de Educação e essa formação deveria estar em consonância com as transformações pelas quais o mundo do trabalho, da cultura e das relações sociais passavam, ou seja, o acirramento do processo de globalização da economia e o desenvolvimento e expansão das Tecnologias da Informação e Comunicação (TICs).

Observamos na educação superior, uma expansão dos investimentos e políticas públicas que favoreceram a iniciativa privada. As políticas educacionais implementadas descaracterizaram o espaço social da educação superior como espaço da investigação e discussão de conhecimentos voltados para as necessidades sociais mais amplas, para voltar-se para questões mais pragmáticas que atendessem às demandas do mercado de trabalho.

Instala-se a pedagogia das competências, justificada pelos seus defensores com base nas mudanças organizacionais do trabalho promovidas pela evolução tecnológica. Opera-se, desse modo, a redução da formação inicial, o que está de acordo com a lógica das mudanças educacionais sob orientação do Banco Mundial, que prevê a formação de um profissional tecnicamente competente a um baixo custo. (SANTOS, 2001, p. 170).

Instituições como Faculdades, Faculdades Integradas e Centros Universitários proliferam no país justificadas pela democratização do ensino e pela necessidade de se 
formar indivíduos para o mercado de trabalho. A formação, já que voltada para o mercado, deveria acontecer de forma aligeirada, o que se concretizou através da redução da carga horária das grades curriculares dos cursos. A formação do professor, "no interior desse paradigma, privilegia o domínio de conteúdos mínimos das disciplinas e a instrumentalização do professor com base em diretrizes e normas curriculares, em detrimento de seu conhecimento pedagógico" (idem, p. 171). Novas modalidades de formação também são autorizadas com base na nova LDB, flexibilizando os espaços de formação, que além de serem oferecidos por Institutos Superiores, poderiam acontecer na modalidade a distância.

O ensino a distância, em sua gênese, tem suas bases consolidadas no modelo fordista que visava à expansão da educação para atender às demandas técnicomecanicistas, em um primeiro momento. Mas, a lógica do sistema, não mais contempla esse modelo de formação ideológica, a expansão da EaD a partir dos anos 90 se estrutura sob um modelo de produção mais flexível, racionalizado, denominado pelos estudiosos de toyotismo ${ }^{1}$. Nesse modelo, o trabalhador deve responder às demandas do mercado flexibilizando suas funções e, para isso, o conhecimento e as relações comunicativas são os principais ingredientes para a integração do indivíduo, o que exige que esse sujeito esteja em contínua formação.

Ao compor esse quadro não quero dizer que as mudanças foram totalmente prejudiciais à Educação e á formação de professores. Mas, afirmar que as transformações não foram devidamente debatidas com os envolvidos no processo, educadores, estudantes e a sociedade em geral, e entendidas pelos mesmos. E ainda, que a formação de professores nessas condições, muitas vezes não responde às necessidades de educação impostas pelo mundo globalizado e se reduz a habilitar um profissional com um conhecimento teórico-prático diminuto, o que dificulta seu entendimento para lidar com a complexidade de situações que emergem na sala de aula.

Contudo, a abertura nas políticas educacionais tem outro lado, o da democratização da escola e do conhecimento. E essa democratização ganha novos foros

1 É um modo de organização da produção capitalista originário do Japão, resultante da conjuntura desfavorável do país. O toyotismo foi criado na fábrica da Toyota no Japão (dando origem ao nome) após a Segunda Guerra Mundial, este modo de organização produtiva, elaborado pelo japonês Taiichi Ohno e que foi caracterizado como filosofia orgânica da produção industrial (modelo japonês), adquirindo uma projeção global. É caracterizado pela mecanização flexível; pelo processo de multifuncionalização de sua mão-de-obra; implantação de sistemas de controle de qualidade total; Sistema just in time; personalização dos produtos; controle visual: Havia alguém responsável por supervisionar as etapas produtivas. Disponível em: http://pt.wikipedia.org/wiki/Toyotismo. Acesso: 10/10/2012. 
com as novas Tecnologias da Informação e Comunicação (TICs) e com desenvolvimento da internet. A inserção das novas Tecnologias da Comunicação e Informação à vida social fez surgir a necessidade de se formar sujeitos capazes de lidar com esses artefatos tecnológicos e a escola como instituição responsável pela educação formal desses sujeitos deve estar preparada teórica e metodologicamente para o ensino, utilizando esses novos modelos de comunicação.

Para isso, os profissionais da educação têm que estar preparados para a prática educativa utilizando esses novos recursos tecnológicos de maneira criativa e proficiente. Mas, não só isso, os professores devem letrar-se no uso dessas ferramentas antes de pensar em qualquer coisa. Nesse sentido, o conceito de letramento amplia-se já que a escrita é veiculada no meio digital. Retomarei essa questão mais adiante. Resta-nos perguntar: quem irá formar esses professores? Onde e quando terão a formação necessária para lidar com as novas TICs no processo de ensino-aprendizagem? E o ensino a distância, foco dessa discussão? Os professores estão preparados para trabalharem com essa modalidade de ensino na sua versão mais recente, utilizando as novas Tecnologias da Informação e Comunicação como meio de interação para o processo de ensino e aprendizagem?

A EaD não é uma novidade trazida pelas novas TICs, como relatado por Moore e Kearsley (2007, p. 25). Ela remonta ao começo dos 1880 , em sua primeira geração, e passa por desenvolvimentos desde então até chegar ao modelo mediado pelas interações via internet, que seria a quinta geração da $\mathrm{EaD}$, que integra em sua interface texto, áudio e vídeo apresentando métodos construtivistas e colaborativos de aprendizagem (MOORE; KEARSLEY, 2007). A expansão da EaD nos últimos anos no Brasil vem justificada institucionalmente pela necessidade de:

acesso crescente a oportunidades de aprendizado e treinamento; proporcionar oportunidades para atualizar aptidões; melhorar a redução de custos dos recursos educacionais; apoiar a qualidade das estruturas educacionais existentes; melhorar a capacitação do sistema educacional; nivelar desigualdades entre grupos etários; direcionar campanhas educacionais para públicos-alvo específicos; aumentar aptidões para a educação em novas áreas de conhecimento; oferecer uma combinação de educação com trabalho e vida familiar; agregar uma dimensão internacional à experiência educacional. (MOORE; KEARSLEY, 2007, p.8).

E com isso a abertura de cursos a distância cresceu sobremaneira, especialmente a partir de 2005, com a adesão das universidades brasileiras na oferta de 
cursos e geração de ambientes virtuais de aprendizagem (AVAs). Mas, e o contingente de professores para atuarem nesses espaços? Nos cursos de formação de professores nos quais trabalhei, em Institutos de Ensino Superior e Faculdades Integradas, as disciplinas que poderiam capacitar o futuro professor a trabalhar com a $\mathrm{EaD}$ eram nomeadas como Informática Aplicada à Educação ou simplesmente Informática e essas apenas trabalhavam no desenvolvimento do que chamarei de alfabetização digital do aluno-professor, ou seja, familiarização dos mesmos no uso do computador, em suas ferramentas operacionais básicas e no uso da internet como instrumento de pesquisa e interação.

$\mathrm{Na}$ verdade, há a necessidade de se entender como funcionam os sistemas operacionais e os "protocolos" de navegação, ou seja, ser alfabetizado digital. Esse conhecimento é decisivo para inserção do futuro professor no mercado de trabalho e da permanência dos que já estão, visto que a alfabetização digital, assim como a alfabetização tipográfica é uma necessidade social de todo e qualquer cidadão. Entretanto, não basta ser alfabetizado digital, é preciso ser letrado digital e conhecer as práticas de leitura e escrita na tela, seus usos, gêneros, interação etc.

Portanto, as aulas de informática, por serem oferecidas em apenas um semestre, não viabilizam o letramento do aluno, tão pouco uma discussão sobre a EaD como opção educativa, muito menos os recursos possíveis para sua implantação na sua versão mais moderna, com o uso da Web 2.0. Tudo isso, porque se "perdia" muito tempo ensinando o futuro professor a simplesmente manusear a máquina. Não basta saber sobre hardware e software, para a inserção na realidade digital do mundo contemporâneo é necessário dominar os gêneros nos quais se configuram as informações e as situações sociais de uso dos textos, os eventos de letramento digital. Buzato (2009, p. 2) apontando Lankshear e Knobel (2007) afirma que no mundo letrado contemporâneo

um novo ethos, uma nova mentalidade que enfatiza a participação, em detrimento da publicação editorial, o conhecimento (técnico) distribuído em lugar do conhecimento (técnico) centralizado, a partilha de conteúdos em vez da propriedade intelectual privada, a experimentação em oposição à normatização, enfim, a troca colaborativa, a quebra de regras criativa e o hibridismo em lugar da difusão de conteúdos, do policiamento e da pureza. 
Ser letrado digital, de acordo com Xavier (s.d.), pressupõe assumir mudanças nos modos de ler e escrever os códigos e sinais verbais e não-verbais, com as imagens e desenhos na tela do computador e todas as possibilidades que o hipertexto propicia. E, além disso, a possibilidade de interação que passa a ser uma intervenção na realidade textual e sociocultural. Ser letrado digital é se "apropriar da nova tecnologia digital e exercer práticas de leitura e de escrita na tela” (SOARES, 2002, p. 151).

O governo federal a fim de ampliar o uso das novas TICs na educação criou o programa ProInfo, que é desenvolvido pela Secretaria de Educação a Distância em parceria com as Secretarias de Educação Estaduais e Municipais. A exemplo disso, na aula do dia 06 de março de 2010 no espaço virtual de aprendizagem promovido pela professora Anna Fricke Matte, nos foi apresentada a estrutura de um curso promovido pela secretaria de educação de Belo Horizonte que capacita os professores da rede municipal no uso de softwares livres e na aplicação das tecnologias do computador no ensino. Esses cursos de capacitação são uma forma de mitigar o problema da falta de domínio do professor no uso das tecnologias, mas eles não resolvem a questão da falta de informação e formação do professor para o ensino a distância.

Vivemos um hiato, característico de um período de transição. Implementamos cursos na modalidade a distância com forte agregado tecnológico, mas não temos ainda professores dos conteúdos específicos, das disciplinas em número suficiente com desenvoltura no uso das novas TICs (CARVALHO, 2007). Estudos realizados pelo Ministério da Educação no primeiro semestre de 2009 mostram que houve um aumento de $90 \%$ no número de matrículas em cursos de graduação em 2008 na modalidade a distância. Desse percentual, 73\% são em instituições particulares de ensino (ABED, 2010). Esses números são muito significativos e requerem uma atenção especial por parte da academia no desenvolvimento de pesquisas que investiguem melhor a EaD e, principalmente, que todas as instituições de ensino dedicadas à formação de professores contemplem na estruturação dos cursos disciplinas que abordem essa modalidade de ensino. A estruturação dos cursos na modalidade a distância deve ser composta por uma equipe multidisciplinar e os professores devem assumir papéis diferenciados, que incluem desde a gestão administrativa dos cursos até a atuação como professor virtual.

O professor de EaD não precisa ser um especialista em tecnologias, ele precisa é ser um usuário hábil e criativo das tecnologias digitais para propor formas de interação 
dos conteúdos das disciplinas ministradas junto aos alunos, motivando-os a uma atitude autônoma de construção do conhecimento. Como afirma Kenski (2003)

Nessa perspectiva não resta apenas ao sujeito adquirir conhecimentos operacionais para poder desfrutar das possibilidades interativas com as novas tecnologias. O impacto das novas tecnologias reflete-se de maneira ampliada sobre a própria natureza do que é ciência, do que é conhecimento. Exige uma reflexão profunda sobre as concepções do que é o saber e sobre as formas de ensinar e aprender (KENSKI,2003, p.75).

Várias são as atribuições dos professores e professores-tutores ${ }^{2}$ na educação a distância, dentre elas Moore e Kearsley (2007, p. 149) destacam:

1. Elaborar o conteúdo do curso;

2. Supervisionar e ser o moderador das discussões;

3. Supervisionar os projetos individuais e em grupo;

4. Dar nota às tarefas e proporcionar feedback sobre o progresso;

5. Manter registros dos alunos;

6. Ajudar os alunos a gerenciar seu estudo;

7. Motivar os alunos;

8. Responder ou encaminhar questões administrativas;

9. Responder ou encaminhar questões técnicas;

10. Responder ou encaminhar questões de aconselhamento;

11. Representar os alunos perante a administração;

12. Avaliar a eficácia do curso.

Essas funções vão muito mais além do que a aula de informática pode ensinar. Ao longo dos cursos de formação de professores nas diversas disciplinas, a EaD deve ser tomada como objeto de estudo, mostrando-a como uma nova forma de se estruturar o ensino. Por exemplo, nas aulas de prática de ensino de Línguas, de Matemática, de História, de Geografia, etc., as metodologias de ensino desenvolvidas por professores e alunos deveriam contemplar a modalidade a distância, refletindo sobre as melhores

${ }^{2}$ O professor-tutor atua como mediador, facilitador, incentivador, investigador do conhecimento, da própria prática e da aprendizagem individual e grupal (ALMEIDA, 2001). A habilidade para planejar, acompanhar e avaliar atividades, bem como motivar o aluno para o estudo, também são relevantes. Na formação pessoal, deve ser capaz de lidar com o heterogêneo quadro de alunos e ser possuidor de atributos psicológicos e éticos: maturidade emocional, empatia com os alunos, habilidade de mediar questões, liderança, cordialidade e, especialmente, a capacidade de ouvir. 
formas de veicular o conteúdo e criando novas práticas de interação para a EaD. Outro exemplo, na disciplina de estrutura e funcionamento escolar, ou denominação similar, a disciplina que trata do funcionamento da escola, seu PPP, currículos, planejamentos diversos, também poderia abordar a modalidade a distância. Todas as disciplinas poderiam ser pensadas nessa lógica, proporcionando ao professor em formação conhecimentos acerca desse paradigma de ensino a distância que é diferente do presencial.

Acredito que com essa tendência que se impõe a cada dia, a da educação a distância, a estrutura curricular dos cursos de formação de professores deverá abordar mais séria e profundamente o assunto. Deverá oferecer disciplinas que, além de promoverem o letramento digital do aluno-professor, habilite-o a trabalhar no ensino a distância, conhecendo as modalidades, ou gerações da EaD, suas ferramentas de ensino e aprendizagem, os ambientes virtuais de aprendizagem, as atribuições do professor, do tutor etc.. Espera-se, com isso, que os futuros professores atribuam, eles mesmos, mais credibilidade ao ensino a distância, disseminando essa modalidade e criando um perfil para o profissional da educação que esteja preparado para trabalhar nessa nova realidade. Nosso papel, enquanto pesquisadores dos cursos de pós-graduação de universidades de todo o país, pode ser esse, o de ajudar a fomentar a EaD como uma alternativa possível para a implementação de um projeto de educação para todos, de qualidade, para que um dia, "aquele que está lá no horizonte", como poetiza Eduardo Galeano, alcancemos a justiça social nesse país.

\section{Referências}

ALMEIDA, F. J. et al. Educação a distância: formação de Professores em Ambientes Virtuais e Colaborativos de Aprendizagem. São Paulo, Projeto NAVE, 2001.

BUZATO, M. E. K. Letramentos digitais, apropriação tecnológica e inovação. In: III encontro nacional sobre hipertexto. Belo Horizonte, 2009.

CARVALHO, A. B . Os múltiplos papéis do professor em educação a distância: uma abordagem centrada na aprendizagem $\mathrm{In}: \mathbf{1 8}^{\circ}$ encontro de pesquisa educacional do Norte e Nordeste - EPENN. Maceió, 2007.

CENSO EAD.BR/ organização da Associação Brasileira de Educação a Distância. São Paulo : Pearson Education do Brasil, 2010.

KENSKI, V. M. Tecnologias e ensino presencial e a distância. São Paulo: Papirus, 2003. 
MOORE, M.; KEARSLEY, G. Educação a distância: uma visão integrada. Trad. Roberto Galman. São Paulo: Thomson Learning, 2007.

SANTOS, S.R. Formação Continuada de professores: a travessia entre Cilas e Caribes. Revista da FAEEBA/Universidade do Estado da Bahia. Departamento de Educação. N. 16. p.169-78. Jul.-Dez. 2001.

SOARES, M. Novas práticas de leitura e escrita: letramento na cibercultura. In: Educação e sociedade. Campinas, vol. 23, n. 81, p. 143-160, dez. 2002. Disponível em: http://www.scielo.br/pdf/es/v23n81/13935.pdf

WIKIPEDIA. Taylorismo. Disponível em: http://pt.wikipedia.org/wiki/Toyotismo Acesso em: 10 out. 2012.

XAVIER, A. C. dos S. Letramento digital e ensino. Online. Disponível em: http://www.ufpe.br/nehte/artigos/Letramento\%20digital $\% 20 \mathrm{e} \% 20$ ensino.pdf. $\quad$ Acesso em: 10 jun. 2010.

Artigo recebido em: 11.10 .2012

Artigo 